\title{
Vitamin B12 for the treatment of vasoplegia in cardiac surgery and liver transplantation: a narrative review of cases and potential biochemical mechanisms Administration de vitamine B12 pour le traitement de la
vasoplégie en chirurgie cardiaque et greffe hépatique : un compte
rendu narratif de cas et des mécanismes biochimiques potentiels
}

Fritz-Gerald Charles, MD • Leslie J. Murray, PhD • Christopher Giordano, MD •

Bruce D. Spiess, MD, FAHA (D)

Received: 19 June 2018/Revised: 14 May 2019/Accepted: 14 May 2019/Published online: 25 July 2019

(C) Canadian Anesthesiologists' Society 2019

\begin{abstract}
Purpose Hydroxocobalamin, or vitamin B12 (V-B12), is frequently used to treat smoke inhalation and cyanide poisoning. Recent reports have also described its use to treat vasoplegia in cardiac surgery and liver transplantation. This narrative review discusses this "offlabel" indication for V-B12, focusing on the potential biochemical mechanisms of its actions.

Source PubMed, Cochrane, and Web of Science databases were searched for clinical reports on the use of V-B12 for vasoplegia in cardiac surgery and liver transplantation, with the biochemical mechanisms discussed being based on a survey of the related biochemistry literature.

Principal findings Forty-four patients have been treated with V-B12 for vasoplegia in various isolated case reports and one series. Although $75 \%$ of patients have increased blood pressure in response to $V$-B12, there were some "nonresponders". The true efficacy remains unknown because clinical trials have not been performed, and significant reporting bias likely exists. Plausible biochemical explanations exist for the potential beneficial effects of $V$ -
\end{abstract}

F.-G. Charles, MD · C. Giordano, MD - B. D. Spiess, MD, FAHA $(\square)$

Department of Anesthesiology, University of Florida College of Medicine, 1600 SW Archer Road, PO Box 100254, Gainesville, FL 32610, USA

e-mail: bspiess@anest.ufl.edu

L. J. Murray, $\mathrm{PhD}$

Department of Chemistry, Center for Catalysis and Florida Center for Heterocyclic Compounds, University of Florida, Gainesville, FL, USA
B12 in treating vasoplegia, including binding nitric oxide and other gasotransmitters. Additional research is required to clarify if and how these mechanisms are causally involved in effective clinical responders and non-responders.

Conclusions Although anecdotal reports utilizing $V$-B12 for vasoplegia are available, no higher-level evidence exists. Future work is necessary to further understand the dosing, timing, adverse events, and biochemical mechanisms of V-B12 compared with other therapies such as methylene blue.

\section{Résumé}

Objectif L'hydroxocobalamine, ou vitamine B12 (V-B12), est fréquemment utilisée pour traiter l'inhalation à la fumée et l'empoisonnement au cyanure. Des comptes rendus récents ont également décrit son utilisation pour le traitement de la vasoplégie en chirurgie cardiaque et en greffe hépatique. Ce compte rendu narratif étudie cette indication "non approuvée » pour la V-B12, en se concentrant sur les mécanismes biochimiques potentiels de ses actions.

Source Les bases de données PubMed, Cochrane et Web of Science ont été passées en revue pour en tirer les comptes rendus cliniques portant sur l'utilisation de la VB12 pour le traitement de la vasoplégie en chirurgie cardiaque et en greffe hépatique, les mécanismes biochimiques discutés se fondant sur une étude de la littérature biochimique associée.

Constatations principales Quarante-quatre patients ont été traités avec de la V-B12 pour une vasoplégie dans divers comptes rendus de cas isolés et dans une série de cas. Bien que la tension artérielle de $75 \%$ des patients 
traités ait augmenté en réponse à l'administration de $V$ B12, il y a eu quelques cas de «non-répondants». L'efficacité véritable de cet agent demeure inconnue parce qu'aucune étude clinique n'a été réalisée, et il existe probablement un biais de publication important. Il existe des explications biochimiques plausibles des effets bénéfiques potentiels de la V-B12 pour le traitement de la vasoplégie, notamment la liaison du monoxyde d'azote et d'autres gazotransmetteurs. Des recherches supplémentaires sont nécessaires pour clarifier si et comment ces mécanismes sont impliqués de manière causale chez les répondants cliniquement significatifs et chez les non-répondants.

Conclusion Bien qu'il existe des comptes rendus anecdotiques sur l'utilisation de la V-B12 pour le traitement de la vasoplégie, il n'existe aucune donnée probante de meilleure qualité. Des recherches supplémentaires sont nécessaires pour mieux comprendre la posologie, le moment d'administration, les événements indésirables et les mécanismes biochimiques de la V-B12 par rapport à d'autres traitements tels le bleu de méthylène.

Hydroxocobalamin, one of the naturally occurring forms of vitamin B12 (V-B12), is approved by the U.S. Food and Drug Administration for the treatment of cyanide $(\mathrm{CN})$ poisoning (by smoke inhalation). ${ }^{1-4}$ Vitamin B12 is also known to prevent the development of pernicious anemia and is important in the production of many hemecontaining cytochromes as well as DNA. Its "off-label" uses include oral V-B12 treatment for Leber's optic atrophy and toxic amblyopia ${ }^{5}$; $\mathrm{CN}$ poisoning is treated with intravenous therapy, as is carbon monoxide (CO) poisoning. ${ }^{1-4}$ The use of super-reduced V-B12, which involves adding two electrons to the central cobalt (Co) atom, treats $\mathrm{CO}$ poisoning in animals. ${ }^{6-8}$ Carbon monoxide poisoning causes profound hypotension refractory to therapy (akin to vasoplegia), and treatment with V-B12 has reversed the hemodynamic phenomenon in animals. ${ }^{6-8}$ Increases in arterial pressure were noted during the four decades of European experience with V-B12 to treat smoke inhalation, which has only been available in the United States since $2006 .{ }^{6}$ Recently, V-B12 has been used "offlabel" to treat the vasoplegic state in cardiopulmonary bypass (CPB) and liver transplantation patients. ${ }^{9-19}$

Vasoplegia is a syndrome (with multiple definitions) of low systemic vascular resistance $\left(<800 \mathrm{dynes}^{-} \mathrm{cm}^{-1} \cdot \mathrm{sec}^{-5}\right)$ and high cardiac output resistant to catecholamine and vasopressin infusions; multiple reviews have previously been published. ${ }^{20-22}$ It is a critical hemodynamic challenge that is associated with mortality rates of $25-50 \% .^{22-30}$
Furthermore, the high doses of vasoconstrictors (phenylephrine, epinephrine, norepinephrine, vasopressin) used to treat the severe hypotension are themselves associated with multiple adverse events. ${ }^{20-22}$ The potential causes of vasoplegia are discussed later in this article, as they may explain how V-B12 can treat this syndrome on a biochemical level, but nitric oxide (NO) overproduction has often been postulated to be causative. Nevertheless, NO overproduction has not been proven to be solely responsible, as it may well be that catecholamine- and angiotensinreduced responsiveness, calcium metabolism, and cyclic nucleotide fluxes may all have interplay. We discuss herein several gasotransmitters that might be affected by V-B12.

The clinical treatment of vasoplegia has frequently focused on the most commonly utilized drug, methylene blue (MB), first reported to treat vasoplegia in Brazil in 1997. ${ }^{31}$ Since then, MB, an azo dye, has been used "offlabel" to treat vasoplegia during and after CPB and liver transplantation. ${ }^{31-37}$ Methylene blue has been extensively reviewed elsewhere and, unlike with V-B12, randomized clinical trials do exist regarding its efficacy in the reduction of both postoperative mortality and renal failure. ${ }^{31-37}$ Methylene blue does not always increase blood pressure, having an approximately $40 \%$ non-response rate. ${ }^{36,37}$ Furthermore, it has recently been found to be toxic to the central nervous system and its use has been linked to increased mortality in some studies. ${ }^{38-41}$ The mechanism of action of MB is hypothesized (though underexplored and not proven) to inhibit the production of $\mathrm{NO}$ via nitric oxide synthase (NOS) and NO-induced activation of guanylate cyclase. $^{15,16,31-38}$ Just as with V-B12, there are no doseresponse or dose-finding studies for $\mathrm{MB}$, and thus healthcare providers have no guidance on dosing. Recent studies have shown that in cases where larger doses of MB ( $>5 \mathrm{mg} \cdot \mathrm{kg}^{-1}$ ) are utilized, MB can be associated with unacceptable side effects such as delayed awakening from anesthesia, neuroapoptosis, and postoperative cognitive dysfunction, as well as hemolysis in patients with glucose6-phosphate deficiency and serotonin syndrome in patients taking serotonin reuptake inhibitors (SSRIs). This is an important finding, as many cardiac patients take these medications. ${ }^{16,37-41}$ Data from the Centers for Disease Control and Prevention show that $13 \%$ of the U.S. population over the age of 12 use antidepressants, most of which are believed to be SSRIs. ${ }^{42}$ The contraindications (e.g., SSRI use), efficacy constraints, and adverse effects of $\mathrm{MB}$ present a need for alternative therapies. In response to that need, intravenous V-B12 has been shown to produce an increase in arterial pressure in $\mathrm{CN}$ poisoning, with minimal adverse side effects. ${ }^{8}$

In the following text, we first summarize the clinical literature available on the "off-label" use of V-B12 to treat vasoplegia in patients who underwent cardiac surgery and 
liver transplantation. We then review the biochemistry of V-B12 and discuss potential mechanisms of action as they might pertain to the treatment of vasoplegia. We conclude by outlining important knowledge gaps and discussing areas requiring future research.

\section{Search methodology}

Literature searches (albeit without a priori methodology or registration in a public database) from PubMed, Cochrane, and Web of Science were undertaken for clinical reports about V-B12 to treat vasoplegia in patients who underwent cardiac surgery and liver transplantation. English language articles with the following search terms were examined: vasoplegic syndrome, vasoplegia, hydroxocobalamin, V-B12, liver transplantation, CPB, intraoperative complications, vascular diseases, systemic inflammatory response syndrome, postoperative complications, intraoperative care, intraoperative period, and bypass. These searches were further informed by the author's indepth working knowledge of metal-chemistry principles.

\section{Clinical evidence base}

Our search found nine case reports and one case series that, when combined, comprised 38 male and six female patients ranging in age from 28 to 83 yr old. ${ }^{9-19}$ All of the case reports and series were reported in the anesthesiology literature either pertaining to CPB or liver transplantation surgery. There were no randomized trials or protocoldriven, hypothesis-based research reports. The Table shows the reports and changes in blood pressure.

Most of the cases described the administration of $5 \mathrm{~g}$ of V-B12 over 15 min. In some cases, V-B12 was infused at continuous rates of 250 or $500 \mathrm{mg} \cdot \mathrm{hr}^{-1}$ until a 5 -g dose was infused. ${ }^{12}$ The exceptions are the cases reported by Gerth et al. and Roderique et al. (Table), which show that an additional dose of $5 \mathrm{~g}$ augmented an improved, though perhaps not satisfactory (to the practitioners), mean arterial pressure (MAP). ${ }^{6,8}$ Some cases reported increased MAP with doses much lower than $5 \mathrm{~g}$. For example, Green et al. (Table) reported an immediate increase of $22 \mathrm{mmHg}$ in MAP with just $125 \mathrm{mg}$ of intravenous V-B12. ${ }^{5}$ Without dose-finding trials, there is no evidence for a minimum, optimal length of effect or repeat dosing. These cases show the need for a dose-response study.

Vitamin B12 has increased MAP in some cases where MB therapy has failed. ${ }^{11,14,15}$ When MB and V-B12 therapies were combined (after failure of $\mathrm{MB}$ ), the increases in MAP ranged from 10 to $40 \mathrm{mmHg}$ (mean increase, $24 \mathrm{mmHg}$ ). ${ }^{11}$ Nevertheless, as that mean was computed from only those cases that actually reported increases, it should be interpreted as potentially biased (because failed responses were not reported).

Conversely, no case report has documented a successful increase in MAP with MB therapy after failed V-B12 therapy. In addition, Schwertner et al. reported two 5-g doses each of V-B12 with only a modest MAP increase, ${ }^{4}$ and Shah et al. reported a case series where nine of 33 patients $(27 \%)$ had no response to $\mathrm{V}-\mathrm{B} 12 .{ }^{11}$ In this particular series, V-B12 was administered to patients who often had not met full criteria for vasoplegia syndrome but were provided V-B12 prophylactically or presumptively (e.g., in response to the surgeon's requests), which may account for some limited responses.

In Shah's series, in addition to group 1 (poor responders, $n=9$ ), patients with other patterns of response to $\mathrm{V}-\mathrm{B} 12$ were separated into group 2 (responders, $n=8$ ), group 3 (responding/sustainers, $n=9$ ), and group 4 (responding/ rebounders, $n=7$ ). All 26 of the patients in groups 2, 3, and 4 responded to $\mathrm{V}-\mathrm{B} 12$ treatment. $^{11}$ The pattern observed in group 4 showed that the response to $\mathrm{V}$-B12 was a hypertensive (vasoconstrictive) one, in which the MAP initially increased to more than $100 \mathrm{mmHg}$ and then declined to $65 \mathrm{mmHg}$. Nevertheless, this decline to 65 $\mathrm{mmHg}$ may have resulted from reducing or even discontinuing the use of other vasoconstrictive drugs. No intraoperative deaths occurred in Shah's series or the other cases reported. All patients survived to the intensive care unit (ICU), with an average postoperative discharge from the ICU at 15 days. The 30-day mortality rate in Shah's series was $12 \%$ (four of 33 ). Note the mortality in untreated vasoplegia $(49 \%)$, vasopressin-treated cases $(32 \%)$, and MB-treated cases $(0-25 \%) .{ }^{11}$ Nevertheless, one cannot infer any mortality effect from these case reports; a prospective head-to-head trial to compare MB and V-B12 is required for this. Nevertheless, in such a trial, a placebo group would likely be considered unethical (even in light of the described rare neuroapoptosis and mortality with $\mathrm{MB}$ at high dosages) with the data existing on MB. A placebo would be deemed "no treatment" for conditions with a high known mortality.

Chromaturia and discolouration of body fluids, such as pink-tinged effluent, discovered during hemodialysis or ultrafiltration with $\mathrm{CPB}$, is described as a side effect of $\mathrm{V}$ B12. Study number 13 described in the Table showed that this effluent colouration produced a false alarm and automatic hemodialysis machine shutdown, which continued for nine days. $^{13,17}$

Five cases of V-B12 administered for CN toxicity (not included in our analysis) similarly caused false blood leak alarms with pink or purple pigmentation of body fluids. ${ }^{13,17}$ Although no other major side effects (other than hypertension) are noted, physicians should be aware of less commonly reported effects, including rash, skin 
reddening, headache, nausea, pruritus, chest discomfort, decreased lymphocytes, and dysphagia. ${ }^{10,14,17}$ Nurses, support personnel, and family members must be informed that the discolouration of urine and body fluids is expected and not harmful.

\section{Chemical activity of V-B12}

\section{Metabolic effects}

Cobalamins are essential in two main cellular reactions: i) connecting lipid and carbohydrate metabolism via the mitochondrial methylmalonyl-CoA mutase conversion of methylmalonic acid to succinate, and ii) activating methionine synthase (synthesizes methionine from homocysteine and 5-methyltetrahydrofolate). ${ }^{43}$ As such, they are required for both heme and DNA synthesis. Cobalamins are transported and utilized in the bone marrow or places wherein active cell division is ongoing. ${ }^{44}$

Vitamin B12 is exclusively synthesized by gut microorganisms through the breakdown of animal proteins, ${ }^{45}$ and is not available from a vegetarian diet. ${ }^{44,45}$ Humans cannot synthesize V-B12; it is absorbed bound to an intrinsic factor (IF) in the distal third of the ileum using receptors that bind selectively to the newly formed complex (B12-IF). Once absorbed, two main transport proteins, transcobalamin I and II, carry it through the plasma to the liver where V-B12 is stored. ${ }^{43-45}$ Vitamin B12 has a halflife of plasma elimination of about $26-31 \mathrm{hr}$ with $50-60 \%$ of it excreted in the urine. ${ }^{43-46}$

\section{Molecular structure of V-B12}

The Co ion in the $1+, 2+$, or $3+$ oxidation state bound within the corrinoid ring (Fig. 1) forms the unique structure of cobalamins. Nitrogen atoms chelate $\mathrm{CO}$ at four equatorial/in-plane coordination sites. One of the two remaining or axial sites on $\mathrm{CO}$ is occupied by a nitrogen atom from a dimethyl-benzimidazole group, linked to the corrinoid ring by a pendant nucleotide. The oxidation state and the identity of the donor in the remaining axial site are variable (Fig. 1), with the latter providing the prefix for the name of the specific cobalamin derivative. For example, axial ligands of hydroxide $\left({ }^{-} \mathrm{OH}\right)$ and ${ }^{-} \mathrm{CN}$ afford the derivatives hydroxocobalamin and cyanocobalamin, respectively. The oxidation state of the Co centre (as absorbed from the gut) is $3+$ as in hydroxocobalamin, although reduced states, such as the $2+$ or $1+$, are known to be biologically relevant and well tolerated. The corrinoid ring of V-B12 bears similarities to the porphyrinoid ring of hemoglobin (Hb), myoglobin, and cytochromes (Fig. 2). For example, both porphyrins and corrins are anionic macrocycles that provide four $\mathrm{N}$ atoms as ligands to the
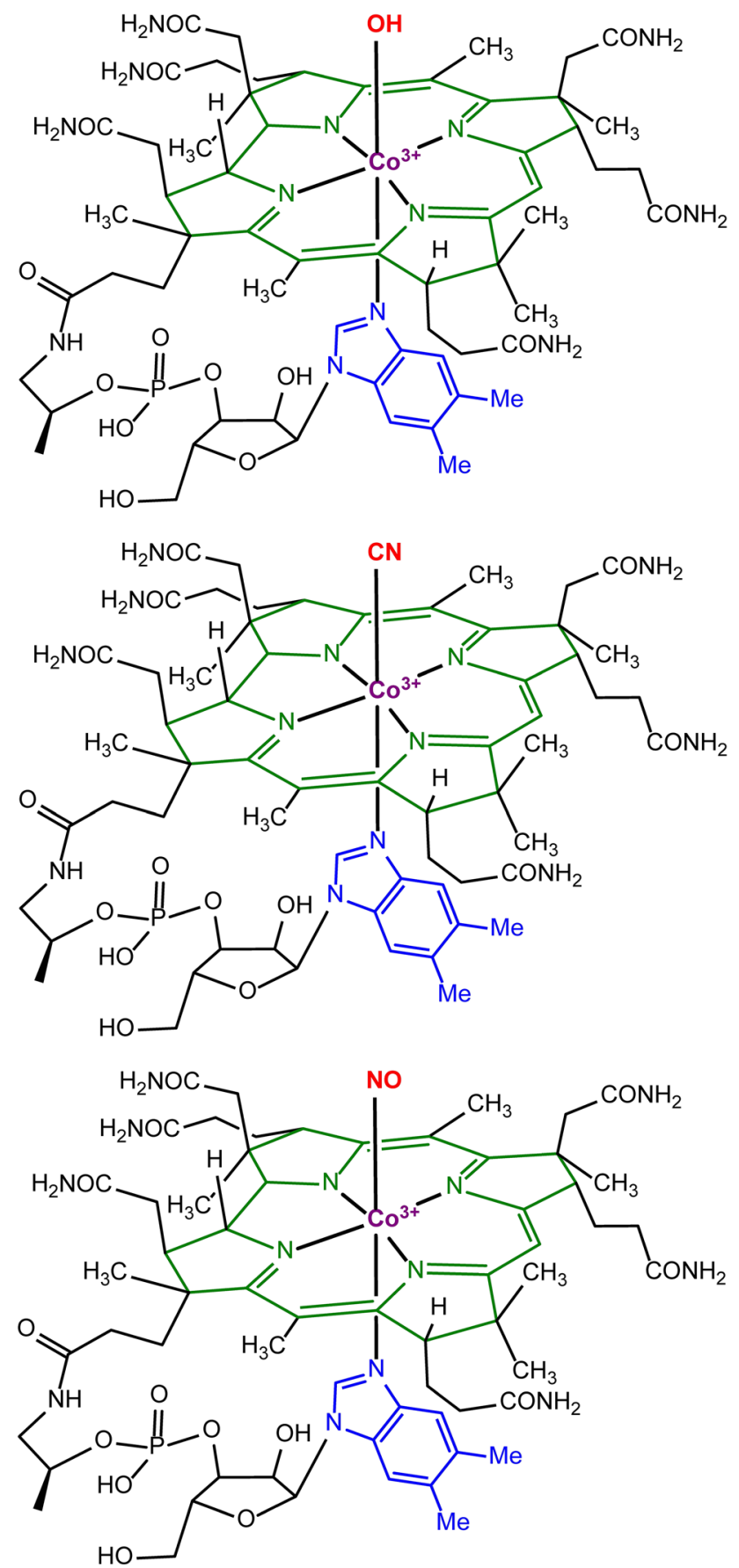

Fig. 1 Structures of cobalamin derivatives of interest. The cobalt ion is depicted in purple, the corrinoid ring or macrocycle with its four $\mathrm{N}$ atom donors bonded to the $\mathrm{Co}^{3+}$ centre is depicted in green, the axial benzimidazole is depicted in blue, and the variable axial ligand (viz, hydroxide $=\mathrm{OH}^{-}$, cyanide $=\mathrm{CN}^{-}$, or nitric oxide $=\mathrm{NO}$ ) is depicted in red (Color figure online)

metal centres. The major difference is the contraction of the ring in the corrinoid $v s$ the porphyrin analogue and the charge of the ring (i.e., -1 for the corrinoids $v s-2$ for the porphyrinoids; Fig. 2). 
Fig. 2 The heme cofactor in hemoglobin in the iron(II) deoxygenated form (left) and the oxygenated iron(III) state after $\mathrm{O}_{2}$ uptake (right). Note the related macrocyclic structure of the porphyrinoid ring and the corrinoid ring of cobalamin, with the differences being the loss of aromaticity and the ring contraction of the latter

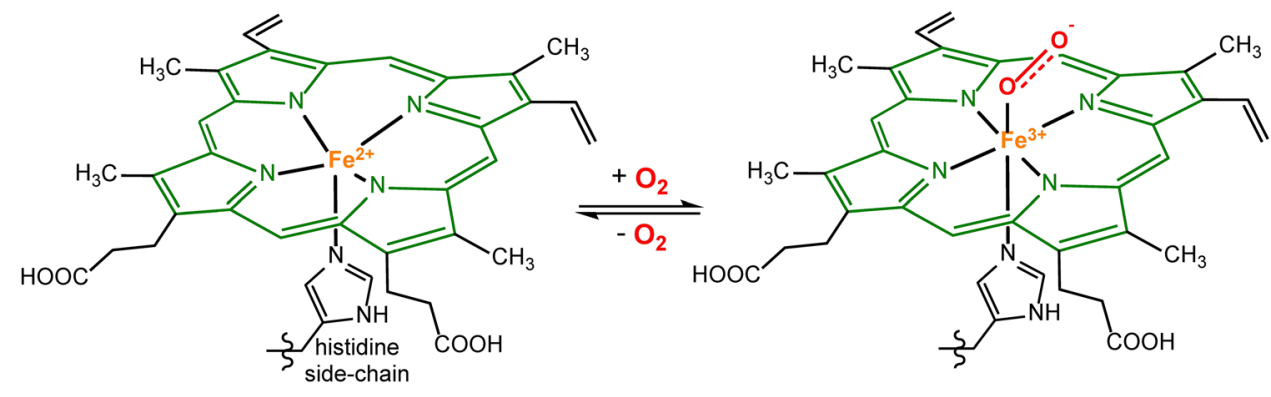

Proposed mechanism of action of V-B12 in vasoplegia

Vasoplegia may result from an unregulated and exaggerated inflammatory response with overwhelming production of endogenous vasodilators that are signalling gases, or so-called gasotransmitters. ${ }^{9-41}$ The mechanisms and biochemistry of reduced responsiveness to catecholamines, angiotensin, and cyclic guanosine monophosphate/calcium are complex. No animal models of vasoplegic shock exist in CPB or liver transplantation. Explanations of the paralytic vascular effects of both septic and hemorrhagic shock all have similarities. Although this focuses on the gasotransmitters, it may be both an overproduction and lack of binding/natural buffering of their production that might lead to the vasoplegia. The gasotransmitters currently identified are NO, hydrogen sulfide $\left(\mathrm{H}_{2} \mathrm{~S}\right)$, and $\mathrm{CO}$. Vitamin B12 interferes with the production and cell signalling of all three gasotransmitters. We will discuss each of these gasotransmitter's effects and relationships to vasoplegia, as well how V-B12 affects them. They each have interplay with inflammation and although the most is known about NO, that does not mean it is the most important, only that it has been the most extensively investigated.

\section{Nitric oxide}

The action of V-B12 with NO depends on two important chemical parameters: 1) the rate constant for the substitution of the axial ligand for NO, and 2) the dissociation constant for the formation of the NO adduct. To review, the reaction rate is the speed at which a chemical reaction occurs. The rate constant correlates to the overall rate and plays a role in determining the reaction rate. The sequence of reactants is reflected in changes in the reaction rate. The dissociation constant for a ligand from a metal centre relates to the energy required to break the metal-ligand bond to liberate the free unassociated ligand in solution. The dissociation constant, therefore, provides information on the relative stability of the metalligand species, with smaller dissociation constants corresponding to greater stability or inertness. Because
$\mathrm{Hb}$ and corrin ring structures have different metals, and therefore different nuclear structures, the understanding of reaction constants is important.

Vitamin B12 acts as an NO sponge by scavenging free NO in the blood. This effective scavenging of NO is consistent with the near diffusion-limited rate constant $\left(2-8 \times 10^{7}\right.$ $\mathrm{M}^{-1} \cdot \mathrm{sec}^{-1}$ ) for substituting hydroxide for NO. ${ }^{4-49}$ The diffusion-controlled rate (i.e., the rate at which two species in solution can diffuse in order to react) is $10^{9}$ to $10^{11}$ $\mathrm{M}^{-1} \cdot \mathrm{sec}^{-1}$. Moreover, the rate constant for loss of NO from nitrosylcobalamin is exceedingly slow $\left(<10^{-5} \mathrm{sec}^{-1}\right)$, ultimately translating into a very small dissociation constant for NO loss once bound to V-B12. ${ }^{47}$ Thus, freely diffusing and water-soluble V-B12 can effectively sequester NO that is liberated near the endothelial cells either within blood vessels or diffusing into the perivascular space. A similar reactivity toward NO is also true for heme cofactors in proteins such as $\mathrm{Hb}$; therefore, other factors must preclude endogenous NO sequestration by heme cofactors involved in oxygen transport. ${ }^{49}$

In addition to scavenging free NO, V-B12 dampens the NO signal, decreasing vasodilation by means of oxygenation. Reduced states of cobalamin (i.e., +2 and $+1)$ react with dioxygen rapidly to generate a superoxocobalamin. ${ }^{50,51}$ This species bears analogy to the early intermediates in cytochrome P450 chemistry in which reactive metal-oxygen species catalyze the oxidation of pharmaceuticals and other compounds. This superoxocobalamin can ultimately oxygenate NO to generate nitrate and nitrite through a peroxynitrite pathway. ${ }^{51,52}$ In essence then, cobalamin may operate as a catalyst in the presence of $\mathrm{O}_{2}$ and reducing agents (e.g., ascorbic acid, which was recently reported to treat vasoplegia to inactivate or suppress NO signalling). ${ }^{53}$ Nevertheless, there remains ongoing debate regarding whether nitrite and nitrate can be considered functionally as stores of $\mathrm{NO}$ - that is, whether nitrate or nitrite can be reduced to release $\mathrm{NO}$ at a later time point. ${ }^{48}$

Nitric oxide synthase is responsible for the production of NO and exists in at least three forms known today (an inducible form and two calmodulin-dependent formsnNOS and eNOS). ${ }^{52}$ Inducible NOS is expressed in 
vascular smooth muscle cells and cardiac myocytes. ${ }^{54}$ Inflammatory mediators (interferon gamma and tumor necrosis factor $\alpha$ ) activate the expression of inducible NOS. $^{52}$

Nitric oxide causes vasodilatation by inducing smooth muscle-soluble guanylate cyclase to increase the production of cyclic guanosine monophosphate. ${ }^{32,48,54,55}$ This results in a reduction of intracellular calcium concentrations, leading to smooth muscle relaxation. ${ }^{54,55}$ As noted previously, VB12-induced hypertension is suggested to arise from NO scavenging. Gerth et al. showed that V-B12, but not its CNbound analogue (cyanocobalamin), was responsible for the increase in arterial blood pressure. ${ }^{6}$ The loss of the hypertensive effect of V-B12 by the non-selective NOS inhibitor L-N $\omega$-nitro-L-arginine methyl ester further corroborates the finding that $\mathrm{NO}$ scavenging is a mechanism for elevating blood pressure. ${ }^{10}$ Vitamin B12 has also been suggested to interfere with the production of NO; cobalamin derivatives and related precursors inhibit inducible NOS in vitro and in vivo. ${ }^{6,55}$ Vitamin B12 inhibits NOS by binding to the active site of the enzyme. ${ }^{55}$ Similarly, V-B12 blocks NO-induced activation of guanylate cyclase, although intercepting the NO signal by V-B12 cannot be excluded. ${ }^{9}$ Cobalamins such as V-B12 exert their hypertensive effects through a multitude of mechanisms. Detecting the principal mechanism could be useful for further development of these analogues in the treatment of vasoplegia.

\section{Hydrogen sulfide}

Hydrogen sulfide is an endothelial-derived hyperpolarizing factor of vascular smooth muscle independent of $\mathrm{NO}^{56}$ Both $\mathrm{NO}$ and $\mathrm{H}_{2} \mathrm{~S}$ bind covalently to regulatory sites found on ion channels involved in vasodilation. Hydrogen sulfide targets the adenosine triphosphate-sensitive potassium channels, leading to vascular smooth muscle hyperpolarization (paralysis of calcium influx to smooth muscle), resulting in vasodilation and a lack of response to vasoconstrictor stimuli. ${ }^{56}$

Hydrogen sulfide is produced by cystathionine gammalyase found in endothelial cells. ${ }^{56}$ It affects small arterioles (resistance). Consequently, $\mathrm{H}_{2} \mathrm{~S}$ has been shown to have a greater effect in the mesenteric arteries than the aorta. ${ }^{46}$ Hydrogen sulfide also causes relaxation via a muscarinic cholinergic-dependent pathway and may stop the conversion of angiotensin I to II. ${ }^{56}$

Hydrogen sulfide is implicated in septic shock, during which the endothelium produces $\mathrm{H}_{2} \mathrm{~S}$ in response to cytokine- or inflammatory-mediated overstimulation. ${ }^{56,57}$ The role of $\mathrm{H}_{2} \mathrm{~S}$ in CPB is unexplored and should be an area of future research. It has been suggested that $\mathrm{H}_{2} \mathrm{~S}$ is important in liver transplantation scenarios, as patients with liver failure cannot break down endogenous or dietaryderived sulfides. ${ }^{56}$ Vitamin $\mathrm{B} 12$ scavenges $\mathrm{H}_{2} \mathrm{~S}$ in vitro to generate a reduced cobalamin derivative with soluble sulfites, which presumably can be cleared by the kidney if similar chemistry occurs in vivo. ${ }^{10,56}$ Animals exposed to $\mathrm{H}_{2} \mathrm{~S}$ poisoning and treated with V-B12 show better survival rates. ${ }^{56}$ Vitamin $\mathrm{B} 12(3+)$ is the form that effectively binds $\mathrm{H}_{2} \mathrm{~S}$ as opposed to its reduced or super-reduced forms. ${ }^{58}$ In vitro, cobalamin derivatives react with $\mathrm{H}_{2} \mathrm{~S}$ to create persulfides, providing one mechanism for influencing $\mathrm{H}_{2} \mathrm{~S}$ signalling. ${ }^{58}$ The US Department of Defense has expressed interest in using V-B12 as an antidote for $\mathrm{H}_{2} \mathrm{~S}$, a gas that can potentially be used as a weapon for chemical warfare. Again, the overproduction of $\mathrm{H}_{2} \mathrm{~S}$ in $\mathrm{CPB}$ and liver transplantation is an area for future research.

\section{Carbon monoxide}

Carbon monoxide is a potent vasodilator and promotes NO release ${ }^{59}$ Endogenously, the production of CO results from the breakdown of senescent erythrocytes through the heme oxidase pathway (a process known as iron scavenging). ${ }^{60}$ In vitro, not only does $\mathrm{V}-\mathrm{B} 12$ bind $\mathrm{CO}$, but reduced V-B12 also catalyzes an oxidation of $\mathrm{CO}$ to carbon dioxide using ascorbate as a cofactor. ${ }^{7,8}$ Ascorbic acid can rapidly reduce/supply electrons to V-B12 to generate the reduced or $\mathrm{Co}^{2+}$ state and super-reduced or $\mathrm{Co}^{1+}$ forms. Native circulating erythrocytes (not having undergone $\mathrm{CPB}$ ) have a high concentration of ascorbic acid, which works as a reducing agent together with glutathione (not with V-B12) to neutralize reactive oxygen species (peroxides) generated by heme cofactors. ${ }^{7,8}$ Reduced V-B12 may be a viable separate drug for the treatment of $\mathrm{CO}$ poisoning, which manifests with vasoplegia, although it should be noted that only animal studies have been performed to explore this. ${ }^{7,8}$

\section{Cobalt in hydroxocobalamin and iron in heme}

Heme proteins with iron in the +2 oxidation state (i.e., $\mathrm{Hb}$, myoglobin, cytochrome $c$ oxidase) have near diffusionlimited rate constants for NO coordination, as well as extraordinarily small dissociation constants (e.g., $10^{-10}$ $10^{-11} \mathrm{M}$ ) for the NO adducts. ${ }^{54}$ Similar to the reaction of $\mathrm{V}-\mathrm{B} 12$ with $\mathrm{NO}, \mathrm{Hb}$ binding $\mathrm{NO}$ is nearly irreversible in the body. Consequently, other factors must limit the reaction of $\mathrm{NO}$ with $\mathrm{Hb}$ (and other heme proteins) to permit NO to be a useful signalling molecule for normal homeostasis. Nitrate and nitrite production and biotransformation is complex. ${ }^{61}$ Hemoglobin and other iron or molybdenum proteins can reduce nitrite to NO, especially in the presence of hypoxia. ${ }^{61}$ These complex interactions are thought to have effects upon ischemia and reperfusion injury. 


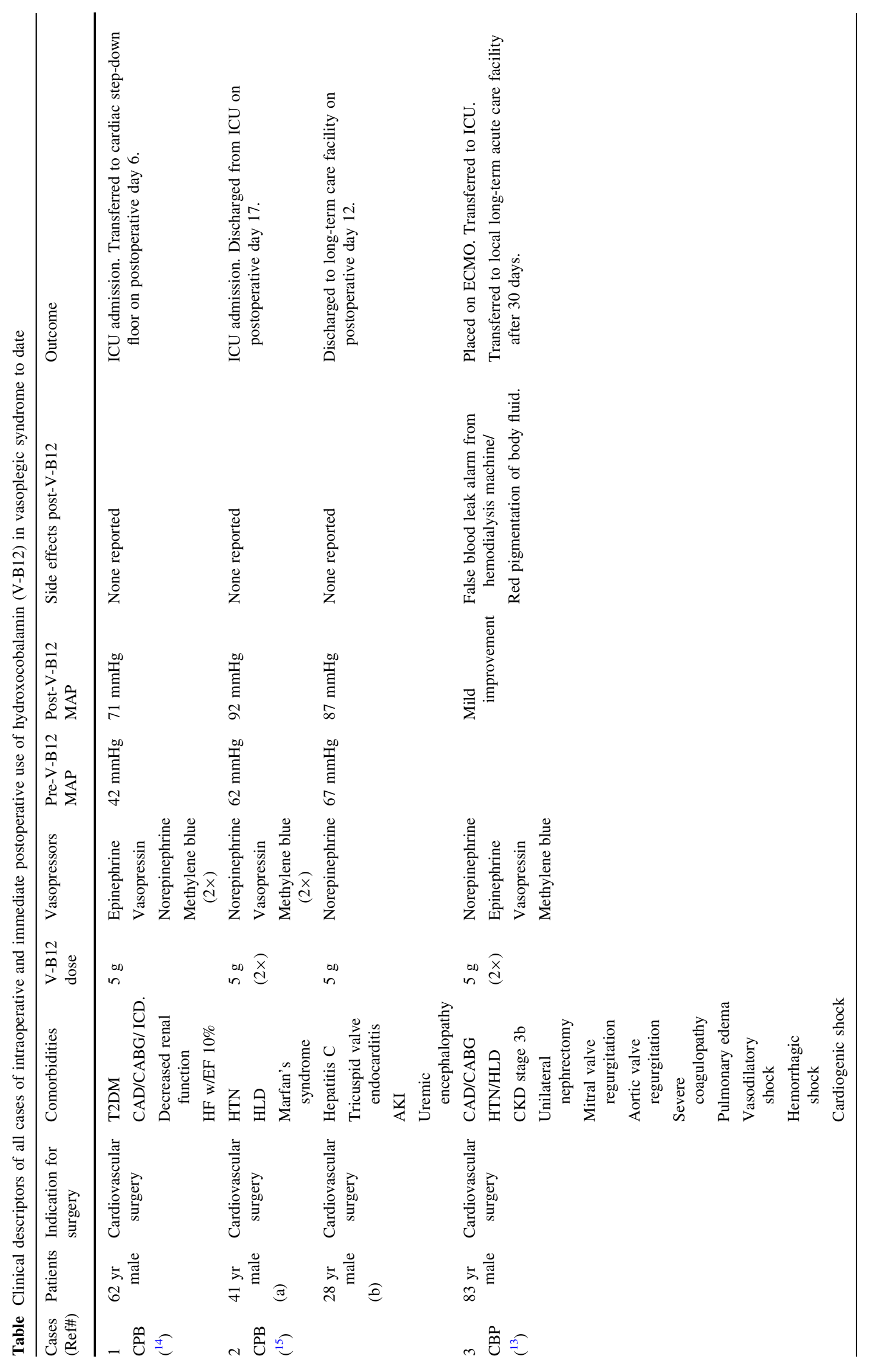




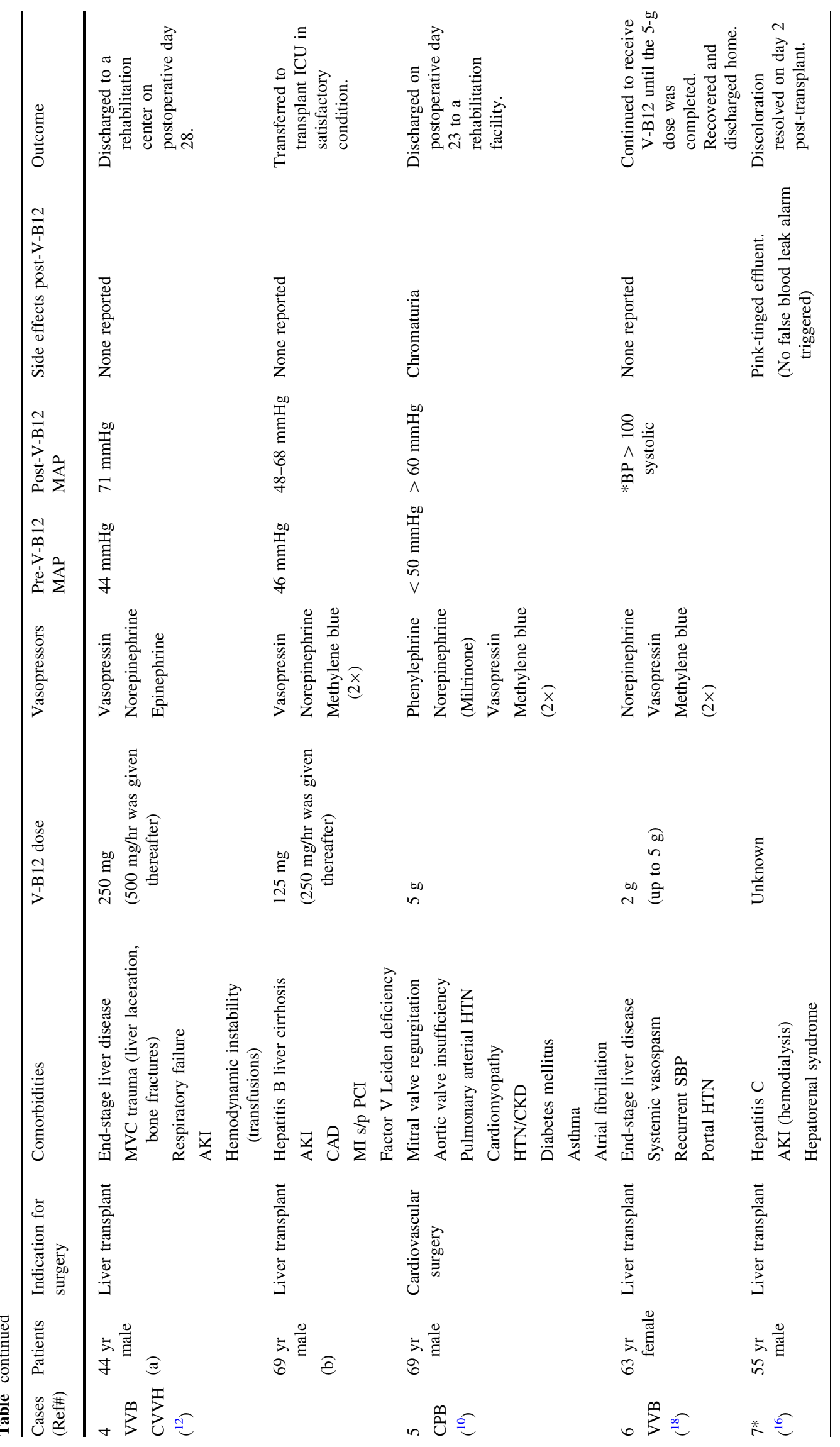




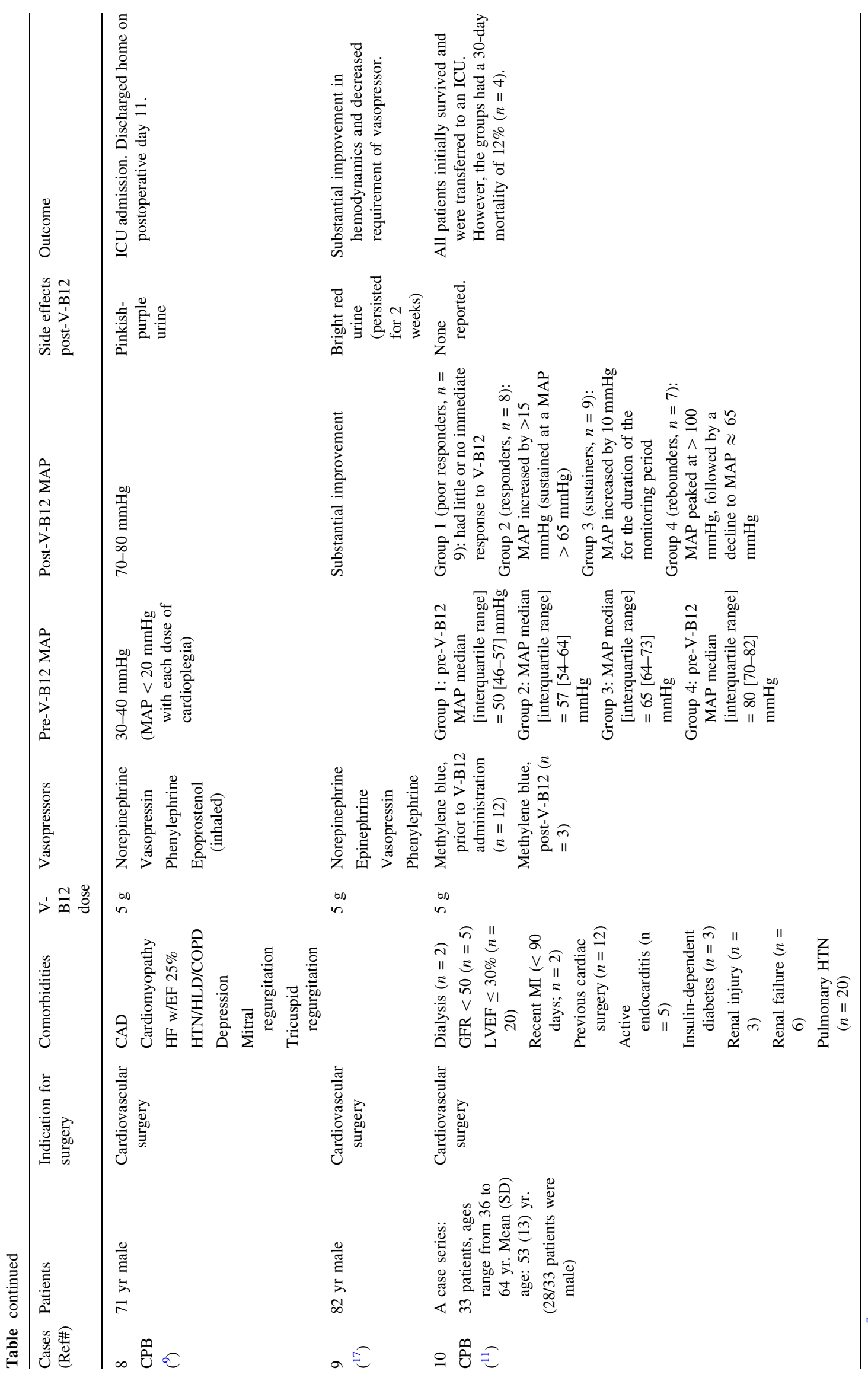

$>\|\| \Perp$

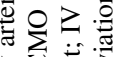

额

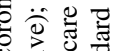

II

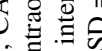

bi

on

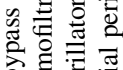

s. ․ㅡㄹ

这要

政

政

政

II 0 范

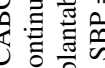

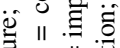

舟

娄记

\&

on :

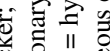

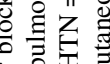

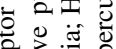

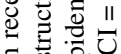

을 은

范

는

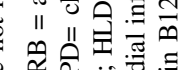

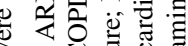

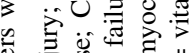

䒠踏

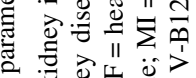

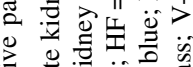

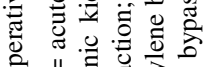

웜 11 记

o 411.0

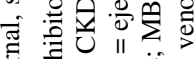

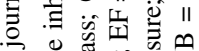

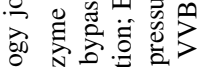

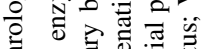

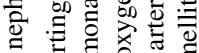

ฐ

उ

要 II

它额 $\sum_{0}^{0}$

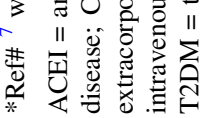


One difference relates to the spatial distribution of $\mathrm{O}_{2}$ carrier proteins (in particular, $\mathrm{Hb}$ ) vs intravenousadministered V-B12. Hemoglobin is compartmentalized within red blood cells in normal physiology, but in CPB and transfusion, significant free $\mathrm{Hb}$ occurs. ${ }^{62,63}$ This erythrocyte containment of $\mathrm{Hb}$ leads to two effects: 1) NO must diffuse through the cell membrane to bind to $\mathrm{Hb}$, and 2) the site of NO production (endothelial cells) is now spatially separated from the red blood cells as a result of fluid dynamics (i.e., red blood cells traverse the centre of blood vessels under positive flow rather than adhering to the vessel walls). ${ }^{54-56}$ In contrast, intravenous administration of V-B12 allows the drug to dissolve in plasma, equating to greater contact with endothelial cell membranes compared with $\mathrm{Hb}$ compartmentalized in erythrocytes. As a result, V-B12 can encounter NO released by endothelial cells before $\mathrm{Hb}$ does, with the overall efficacy dictated by the relative concentrations of V-B12 and NO near the endothelial cells. Intravenous concentration of administered V-B12 should be studied pharmacodynamically to understand NO production and $\mathrm{V}$ B12 binding.

The chemistry of Hycob and Cycob can help explain the properties of $\mathrm{V}-\mathrm{B} 12$

In $\mathrm{CN}$ poisoning, the $\mathrm{Co}$ ion in $\mathrm{V}-\mathrm{B} 12$ binds $\mathrm{CN}$, resulting in the formation of cyanocobalamin (Cycob; nontoxic, renal excretion). We postulate that the primary mechanism for V-B12-induced hypertension is NO scavenging by the Co ion to generate nitrosylcobalamin. ${ }^{61}$ The oxidation state of Co is critical to sequester NO. Vitamin B12 is thought to be most reactive in the $2+$ (reduced) or super-reduced $(1+)$ forms, with the $3+$ form (as sold and isolated) being much less reactive. ${ }^{59-67}$ Roderique $e t$ al. noted that super-reduced and reduced $\mathrm{V}-\mathrm{B} 12$ were the only effective redox-states of $\mathrm{V}$-B12 for CO removal, though they could not distinguish which species was more important. ${ }^{7}$

The importance of the second axial ligand for these chemical reactions in V-B12 contrasted to cyanocobalamin is important. These two molecules share the corrinoid and axial benzimidazole ligands and differ only at the sixth coordination site on the central $\mathrm{Co}$ atom, wherein the hydroxyl $(-\mathrm{OH})$ group of $\mathrm{V}-\mathrm{B} 12$ is replaced with the $-\mathrm{CN}$. Given the donor strength differences for hydroxide vs $\mathrm{CN}$, the ease of substitution of this variable ligand differs greatly between Cycob and V-B12, with V-B12 undergoing facile exchange of the hydroxide with other potential ligands and Cycob being orders of magnitude slower for exchange of the $\mathrm{CN}$. Unlike the postulated NO scavenging or sequestration mechanism of V-B12, Cycob is unable to produce an analogous increase in blood pressure and systemic vascular resistance as seen with $\mathrm{V}$ -
B12, consistent with the slower kinetics for NO substitution of $\mathrm{CN}$ compared with hydroxide. ${ }^{14,60}$ In summary, V-B12 is likely much more effective than Cycob at binding NO because the substitution kinetics and dissociation constants substantially favour loss of hydroxide compared with $\mathrm{CN}$. This mechanism is predicated on the sixth ligand dissociating or leaving to provide an open coordination site on the metal centre prior to NO binding (Fig. 2).

Vitamin B12 use in sepsis and hemorrhage

In addition to the possible role in the treatment of vasoplegia, V-B12 may also be useful in hemorrhagic shock/trauma. Severe hemorrhage is associated with high NO levels. ${ }^{67,68}$ Thus, V-B12 may be a viable, temporary resuscitation treatment option when blood is unavailable, but it has not been tested in a trial. ${ }^{67}$ The increase in NO in hemorrhagic shock (and septic shock) results from upregulation of NOS by inflammatory cytokines, as well as the release of $\mathrm{H}_{2} \mathrm{~S} .{ }^{66}$ Bebarta et al. noted $\mathrm{V}-\mathrm{B} 12$ increased blood pressure and systemic vascular resistance in a hypovolemic hemorrhage swine model. ${ }^{68}$

$\mathrm{Xu}$ et al., noted that vascular reactivity (i.e., vascular responsiveness to vasoconstrictors and vasodilators) increased in the early stage of trauma shock and decreased in late stages. ${ }^{69}$ Angiopoietin-1 and -2 may regulate this biphasic change. While angiopoietin-1 causes hyperactivity in early stages of shock via the Tie2-AkteNOS pathway, it leads to an appropriate release of NO. Nevertheless, it is believed that angiopoietin-2 is the main culprit for the hypo-reactivity in the late stages of shock via the Tie2-Erk-iNOS pathway, as it leads to the release of extensive amounts of NO. ${ }^{69}$ This increase in NO during hemorrhagic shock has been the primary driver for the increased scientific interests in NOS inhibitors and NO scavengers, and thus, V-B12. Although this example discusses the possible synergy of mechanisms in trauma rather than $\mathrm{CPB}$ or liver transplantation, these mechanisms may be an important point of focus for researchers.

\section{Future directions and conclusions}

A summary of the clinical cases reported to date show that the "off-label" use of V-B12 often, but not always, increases blood pressure when vasoplegia is suspected in cardiac surgery and liver transplantation. Vitamin B12 inhibits, binds, and in certain instances, removes all three gasotransmitters that are potentially involved. There are animal models of septic and hemorrhagic shock, so mechanisms can be investigated in laboratories. But there 
are no models of CPB or liver transplantation vasoplegic shock.

Importantly, however, serious reporting bias likely exists for these cases; i.e., if V-B12 was utilized for what was thought to be vasoplegia and it failed to produce a response, this was likely not reported. In the case series presented herein, "non-responders" existed, but we do not know if they were anticipated to develop a response and did not.

This article is put forward to promote hypothesis generation and ideally to stimulate future randomized trials. The knowledge gaps are large. Although V-B12 use presented herein sounds promising, cautionary words need to be put forth. A clinical trial of a NOS inhibitor (546C88) was terminated early because of unexpected numbers of deaths in the group that received the drug. ${ }^{70}$ Thus, caution maybe needed in the use of blanket inhibition of $\mathrm{NO}, \mathrm{CO}$, or $\mathrm{H}_{2} \mathrm{~S}$ as this may well have unintended consequences.

Research to determine appropriate dosing range (minimum, maximum, and average effective dose) is now called for. It is reported that the use of MB concomitantly with V-B12 may produce a better side effect profile when compared with high doses of catecholamines in situations such as vasospasm, although level 1 evidence is lacking. ${ }^{16}$ The biochemistry of V-B12 reviewed here should be considered by researchers as they design future studies, perhaps looking for biomarkers of sulfites and NOcobalamin derivatives. Benchtop research needs to be conducted based on the knowledge of binding constants and other related factors. Although early in clinical practice and with much research yet to be done, we propose that $\mathrm{V}$ B12 should undergo expanded trials.

\section{Acknowledgements The authors wish to acknowledge the editorial support of Adriana Barbat and Corey Astrom, ELS, who were instrumental in the preparation and professional development of this paper. Drs. Joseph Roderique, MD, MS, Lt. US Navy and Penelope Reynolds, $\mathrm{PhD}$, though not authors, have also been instrumental in many of the thoughts and in the development of the concept of using V-B12 in vasoplegia.}

Conflicts of interest None of the authors have conflicts of interest with regard to vitamin B12 or vasoplegia. Dr. Spiess discloses that he has shared patents with Virginia Commonwealth University and others for pharmacologically changed (reduced) vitamin B12 in the treatment of carbon monoxide poisoning, which is not the subject of this manuscript.

Editorial responsibility This submission was handled by Dr. Hilary P. Grocott, Editor-in-Chief, Canadian Journal of Anesthesia.

Author contributions All authors contributed substantially to all aspects of this manuscript, including study conception and design, acquisition and interpretation of data, and drafting the article. FritzGerald Charles performed the initial literature review, case research, participated in all discussions of mechanisms, and wrote the primary manuscript. Leslie J. Murray performed the literature review for the chemistry aspects, led discussions regarding the biochemistry, and participated in editing and review of all aspects of this manuscript. Christopher Giordano reviewed the liver transplantation data, coordinated the writing, mentored Dr. Charles, and participated in all discussions regarding literature and biochemistry, as well as reviewing and editing the manuscript. Bruce D. Spiess contributed the original concept, asked the basic biochemical questions, and expressed the hypotheses that began this group by doing a literature and biochemical review. He was lead and final editor on revisions.

Funding This research did not receive any specific grant from funding agencies in the public, commercial, or not-for-profit sectors.

\section{References}

1. MacLennan L, Moiemen N. Management of cyanide toxicity in patients with burns. Burns 2015; 41: 18-24.

2. Nguyen L, Afshari A, Kahn SA, McGrane S, Summitt B. Utility and outcomes of hydroxocobalamin use in smoke inhalation patients. Burns 2017; 43: 107-13.

3. Broderick KE, Poltluri $P$, Zhuang $S$, et al. Cyanide detoxification by the cobalamin precursor cobinamide. Exp Biol Med (Maywood) 2006; 231: 641-9.

4. Schwertner HA, Valtier S, Bebarta VS. Liquid chromatographic mas spectorometric (LC/MS/MS) determination of plasma hydroxocobalamin and cyanocobalamin concentrations after hydroxocobalamin antidote treatment for cyanide poisoning. $\mathrm{J}$ Chromatogr B Analyt Technol Biomed Life Sci 2012; 905: 10-6.

5. Green R, Allen LH, Bjørke-Monsen AL, et al. Vitamin $\mathrm{B}_{12}$ deficiency. Nat Rev Dis Primers 2017; 3: 17040.

6. Gerth $K$, Ehring $T$, Braendle $M$, Schelling $P$. Nitric oxide scavenging by hydroxocobalamin may account for its hemodynamic profile. Clin Toxicol (Phila) 2006; 44(Suppl 1): 29-36.

7. Roderique JD, Josef CS, Newcomb AH, Reynolds PS, Somera LG, Spiess $B D$. Preclinical evaluation of injectable reduced hydroxocobalamin as an antidote to acute carbon monoxide poisoning. J Trauma Acute Care Surg 2015; 79(4 Supple 2): S116-20.

8. Roderique JD, Josef CS, Feldman MJ, Spiess BD. A modern literature review of carbon monoxide poisoning theories, therapies, and potential targets for therapy advancement. Toxicology 2015; 334: 45-58.

9. Roderique JD, VanDyck K, Holman B, Tang D, Chui B, Spiess $B D$. The use of high-dose hydroxocobalamin for vasoplegic syndrome. Ann Thorac Surg 2014; 97: 1785-6.

10. Burnes ML, Boettcher BT, Woehlck HJ, Zundel MT, Igbal Z, Pagel PS. Hydroxocobalamin as a rescue treatment for refractory vasoplegic syndrome after prolonged cardiopulmonary bypass. J Cardiothoracic Vasc Anesthesia 2017; 31: 1012-4.

11. Shah PR, Reynolds PS, Pal N, Tang D, McCarthy H, Spiess BD. Hydroxocobalamin for the treatment of cardiac surgeryassociated vasoplegia: a case series. Can J Anesth 2018; 65: 560-8.

12. Boettcher BT, Woehlck HJ, Reck SE, et al. Treatment of vasoplegic syndrome with intravenous hydroxocobalamin during liver transplantation. J Cardiothoracic Vasc Anesth 2017; 31: 1381-4.

13. Cheungpasitporn W, Hui J, Kashani KB, Wittwer ED, Albright $R C J r$, Dillon $J J$. High-dose hydroxocobalamin for vasoplegic syndrome causing false blood leak alarm. Clin Kidney J 2017; 10: $357-62$. 
14. Cai $Y$, Mack A, Ladlie BL, Martin AK. The use of intravenous hydroxocobalamin as a rescue in methylene blue-resistant vasoplegic syndrome in cardiac surgery. Ann Card Anaesth 2017; 20: 462-4.

15. Zundel MT, Feih JT, Rinka JR, et al. Hydroxocobalamin with or without methylene blue may improve fluid balance in critically ill patients with vasoplegic syndrome after cardiac surgery: a report of two cases. J Cardiothorac Vasc Anesth 2018; 32: 452-7.

16. Gizaw A, Kidd JM. All that leaks is not blood. Kidney Int 2015; 88: 645.

17. Warner MA, Mauermann WJ, Armour S, Barbara DW. Red urinary discolouration following hydroxocobalamin treatment for vasoplegic syndrome. Can J Anesth 2017; 64: 673-4.

18. Woehlck HJ, Boettcher BT, Lauer KK, et al. Hydroxocobalamin for vasoplegic syndrome in liver transplantation: restoration of blood pressure without vasospasm. A A Case Rep 2016; 7: 24750 .

19. Boettcher BT, Woehlck HJ, Reck SE, et al. Treatment of vasoplegia syndrome with intravenous hydroxocobalamin during liver transplantation. J Cardiothorac Vasc Anesth 2017; 31: 1381-4.

20. Levy B, Fritz C, Tahon E, Jacquot A, Auchet T, Kimmoun A. Vasoplegia treatments: the past, the present, and the future. Crit Care 2018; 22: 52.

21. Shaefi S, Mittel A, Klick J, et al. Vasoplegia after cardiovascular procedures- pathophysiology and targeted therapy. J Cardiothorac Vasc Anesth 2018; 32: 1013-22.

22. Fischer GW, Levin MA. Vasoplegia during cardiac surgery: current concepts and management. Semin Thorac Cardiovasc Surg 2010; 22: 140-4.

23. Levin MA, Lin HM, Castillo JG, Adams DH, Reich DL, Fischer $G W$. Early on-cardiopulmonary bypass hypotension and other factors associated with vasoplegic syndrome. Circulation 2009; 120: $1664-7$.

24. Omar S, Zedan A, Nugent $K$. Cardiac vasoplegia syndrome: pathophysiology, risk factors and treatment. Am J Med Sci 2015; 349: 80-8.

25. Mekontso-Dessap A, Houël R, Soustelle C, Kirsch M, Thébert D, Loisance DY. Risk factors for post-cardiopulmonary bypass vasoplegia in patients with preserved left ventricular function. Ann Thorac Surg 2001; 71: 1428-32.

26. Gromes WJ, Carvahlho AC, Palma JH, et al. Vasoplegic syndrome after open heart surgery. J Cardiovasc Surg (Torino) 1998; 39: 619-23.

27. Cremer J, Martin M, Redl H, et al. Systemic inflammatory response syndrome after cardiac operations. Ann Thorac Surg 1996; 61: 1714-20.

28. Carrel T, Englberger L, Mohacsi P, Neidhart P, Schmidli J. Low systemic vascular resistance after cardiopulmonary bypass: incidence, etiology, and clinical importance. J Card Surg 2000; 15: 347-53.

29. Pandya NR, Alphonso N, Tu Q, Venugopal P, Schlapbach LJ. Prolonged postoperative vasoplegia in pediatric patients on chronic angiotensin II blocker treatment. Front Cardiovasc Med 2018; 5: 121 .

30. Lambden S, Creagh-Brown BC, Hunt J, Summers C, Forni LG. Definitions and pathophysiology of vasoplegic shock. Crit Care 2018; 22: 174.

31. Evora PR, Ribeiro PJ, de Andrade JC. Methylene blue administration in SIRS after cardiac operations. Ann Thorac Surg 1997; 63: 1212-3.

32. Shanmugam $G$. Vasoplegic syndrome-the role of methylene blue. Eur J Cardiothorac Surg 2005; 28: 705-10.

33. Maslow AD, Stearns G, Butala P, Schwartz CS, Gough J, Singh $A K$. The hemodynamic effects of methylene blue when administered at the onset of cardiopulmonary bypass. Anesth Analg 2006; 103: 2-8.

34. Juffermans NP, Vervloet MG, Daemen-Gubbels CR, Binnekade $J M$, deJong $M$, Groeneveld $A B$. A dose-finding study of methylene blue to inhibit nitric oxide actions in the hemodynamics of human septic shock. Nitric Oxide 2010; 22: 275-80.

35. Booth AT, Melmer PD, Tribble B, MeHaffey JH, Tribble C. Methylene blue for vasoplegic syndrome. Heart Surg Forum 2017; 20: E234-8.

36. Mehaffey JH, Johnston LE, Hawkins RB, et al. Methylene blue for vasoplegic syndrome after cardiac operation: early administration improves survival. Ann Thorac Surg 2017; 104: 36-41.

37. Evora PR, Alves Junior L, Ferreira CA, et al. Twenty years of vasoplegic syndrome treatment in heart surgery. Methylene blue revised. Rev Bras Cir Cardiovasc 2015; 30: 84-92.

38. Hencken L, To L, Ly N, Morgan JA. Serotonin syndrome following methylene blue administration for vasoplegic syndrome. J Card Surg 2016; 31: 208-10.

39. Hanna ER, Clark JA. Serotonin syndrome after cardiopulmonary bypass: a case demonstrating the interaction between methylene blue and selective serotonin reuptake inhibitors. A A Case Rep 2014; 2 : 113-4.

40. Werner I, Guo F, Bogert NV, et al. Methylene blue modulates transendothelial migration of peripheral blood cells. PLoS One 2013; 8: e82214.

41. Weiner MM, Lin HM Danforth D, Rao S, Hosseinian L, Fischer $G W$. Methylene blue is associated with poor outcomes in vasoplegic shock. J Cardiothoracic Vasc Anesth 2013; 27: 1233-8.

42. Pratt LA, Brody DJ, Gu Q. Antidepressant use among persons aged 12 and over: United States, 2011-2014. NCHS Data Brief 2017; 283: 1-8.

43. Trevor AJ, Katzung BG, Kruidering-Hall $M$. Agents used in cytopenias; hematopoietic growth factors. In: Trevor AJ, Katzung BG, Kruidering-Hall M, editors. Katzung \& Trevor's Pharmacology: Examination \& Board Review. 11th ed. New York, NY: McGraw-Hill; 2015. p. 270.

44. Hoffbrand $A V$. Megaloblastic anemias. In: Kasper D, Fauci A, Hauser S, Longo D, Jameson J, Loscalzo J, editors. Harrison's Principles of Internal Medicine. 19th ed. New York, NY: McGraw-Hill; 2014 .

45. Bender DA. Micronutrients: vitamins \& minerals. In: Rodwell VW, Bender DA, Botham KM, Kennelly PJ, Weil P, editors. Harper's Illustrated Biochemistry. 30th ed. New York, NY: McGraw-Hill; 2015. p. 546.

46. UpToDate ${ }^{\circledR}$. Hydroxocobalamin (vitamin B12a supplement and cyanide antidote): Drug information - 2018. Available from URL: https://www.uptodate.com/contents/hydroxocobalamin-vitaminb12a-supplement-and-cyanide-antidote-drug-information?search $=$ cyanokit\&source $=$ search_result\&selectedTitle $=1 \sim 148 \&$ usage_ type $=$ default $\&$ display_rank=1 (accessed May 2019).

47. Cooper $C E$. Nitric oxide and iron proteins. Biochim Biophys Acta 1999; 1411: 290-309.

48. Helms C, Kim-Shapiro DB. Hemoglobin-mediated nitric oxide signaling. Free Radic Biol Med 2013; 61: 464-72.

49. Wolak M, Zahl A, Schneppensieper T, Stochel G, van Eldik R. Kinetics and mechanism of the reversible binding of nitric oxide to reduced cobalamin B(12r) (Coba(II)alamin). J Am Chem Soc 2001; 123: 9780-91.

50. Brouwer BM, Chamulitrat W, Ferruzzi G, Sauls DL, Weinberg $J B$. Nitric oxide interactions with cobalamins: Biochemical and functional consequences. Blood J 1996; 5: 1857-64.

51. Kruszyna H, Magyar JS, Rochelle $L G$, et al. Spectroscopic studies of nitric oxide (NO) interactions with cobalamins: 
Reaction of NO with superoxocobalamin (III) likely accounts for cobalamin reversal of the biological effects of NO. J Pharmacol Exp Ther 1998; 285: 665-71.

52. Gaston B, Drazen JM, Loscalzo J, Stamler JS. The biology of nitrogen oxides in the airways. Am J Respir Crit Care Med 1994; 149(2 Pt 1): 538-51.

53. Wieruszewski PM, Nei SD, Maltais S, Schaff HV, Wittwer ED. Vitamin $C$ for vasoplegia after cardiopulmonary bypass: A case series. A A Pract 2018; 11: 96-9.

54. Archer SL, Huang JM, Hampl V, Nelson DP, Shultz PJ, Weir EK. Nitric oxide and cGMP cause vasorelaxation by activation of a charybdotoxin-sensitive K channel by cGMP-dependent protein kinase. Proc Natl Acad Sci U S A 1994; 91: 7583-7.

55. deMartino AW, Kim-Shapiro DB, Patel RP, Gladwin MT. Nitrite and nitrate chemical biology and signalling. $\mathrm{Br} \mathrm{J}$ Pharmacol 2019; 176: 228-45.

56. Mustafa AK, Sikka G, Gazi SK, et al. Hydrogen sulfide as endothelial-derived hyperpolarizing factor sulfhydrates potassium channels. Circ Res 2011; 109: 1259-68.

57. Gaddam RR, Chambers S, Murdoch D, Shaw G, Bhatia M. Circulating levels of hydrogen sulfide and substance $P$ in patients with sepsis. J Infect 2017; 75: 293-300.

58. Salnikov DS, Kucherenko PN, Dereven'kov IA, Makarov SV, van Eldik $R$. Kinetics and mechanism of the reaction of hydrogen sulfide with cobalamin in aqueous solution. Eur J Inorg Chem 2014; 5: 852-62.

59. Thorup C, Jones CL, Gross SS, Moore LC, Goligorsky MS. Carbon monoxide induces vasodilation and nitric oxide release but suppresses endothelial NOS. Am J Physiol 1999; 277: F8829.

60. Owens EO. Endogenous carbon monoxide production in disease. Clin Biochem 2010; 43: 1183-8.

61. Weinberg JB, Chen Y, Jiang N, Beasley BE, Salerno JC, Ghosh $D K$. Inhibition of nitric oxide synthase by cobalamins and cobinamides. Free Radic Biol Med 2009; 46: 1626-32.
62. Vermeulen Windsandt IC, de Wit NC, Sertorio JT, et al. Blood transfusions increase circulating plasma free hemoglobin levels and plasma nitric oxide consumption: a prospective observational pilot study. Crit Care 2012; 16: R95.

63. Vercaemst L. Hemolysis in cardiac surgery patients undergoing cardiopulmonary bypass: a review in search of a treatment algorithm. J Extra Corpor Technol 2008; 40: 257-67.

64. Bauer JA. Synthesis, characterization and nitric oxide release profile of nitrosylcobalamin: a potential chemotherapeutic agent. Anticancer Drugs 1998; 9: 239-44.

65. Zheng $D$, Birke RL. Spectroscopic evidence for nitric oxide binding with cob(II)alamin. J Am Chem Soc 2001; 123: 4637-8.

66. Danishpajooh IO, Gudi T, Chen Y, Kharitonov VG, Sharma VS, Boss GR. Nitric oxide inhibits methionine synthase activity in vivo and disrupts carbon flow through the folate pathway. $J$ Biol Chem 2001; 276: 27296-303.

67. Kambo A, Sharma VS, Casteel DE, Woods VL Jr, Pilz RB, Boss $G R$. Nitric oxide inhibits mammalian methylmalonyl-CoA Mutase. J Biol Chem 2005; 280: 10073-82.

68. Bebarta VS, Garrett N, Boudreau S, Castaneda M. A prospective, randomized trial of intravenous hydroxocobalamin versus whole blood transfusion compared to no treatment for class III hemorrhagic shock resuscitation in prehospital swine model. Acad Emerg Med 2015; 22: 321-30.

69. Xu J, Lan D, Li T, Yang G, Liu L. Angiopoietins regulate vascular reactivity after haemorrhagic shock in rats through the Tie2-nitric oxide pathway. Cardiovasc Res 2012; 96: 308-19.

70. López A, Lorente JA, Steingrub J, et al. Multiple-center, randomized, placebo-controlled, double-blind study of the nitric oxide synthase inhibitor 546C88: effect on survival in patients with septic shock. Crit Care Med 2004; 32: 21-30.

Publisher's Note Springer Nature remains neutral with regard to jurisdictional claims in published maps and institutional affiliations. 